Peppler, K. A., Downton, M. P., Lindsay, E., and Hay, K. (2011). The Nirvana Effect: Tapping video games to mediate music learning and interest. International Journal of Learning and Media.

\title{
THE NIRVANA EFFECT: \\ TAPPING VIDEO GAMES TO MEDIATE MUSIC LEARNING AND INTEREST
}

\author{
Kylie Peppler, Michael Downton, Eric Lindsay and Kenneth Hay \\ Indiana University, Bloomington
}

\begin{abstract}
While rhythmic video games like Rock Band have enormous popularity, little attention has been paid to these types of games for their potential for music education. This is a missed opportunity, as the music concepts central to the comprehension of traditionally notated music, we believe, are embodied in rhythmic games' notation system, including models of metric hierarchy, subdivision, and pattern identification. Furthermore, the game's alternative notation serves as a novice-friendly method whose lessons can be applied to more traditional forms of notation, affording learners a way into more formal practices. To investigate these possibilities, our study identified 26 youth from an afterschool club with little to no prior experience with rhythmic video games to engage in Rock Band over the course of nine months. Analyzing the learning using a sociocultural framework, we sought to understand the relationship between players' familiarity with the Rock Band notation and competence with traditional music concepts. Findings suggest that the ways which music is represented in Rock Band provides players with a "doorway in" to more formal music practices through heightening players' interest and abilities in music. Implications for connecting out-of-school learning to the goals of the classroom are discussed.
\end{abstract}




\section{INTRODUCTION}

Around the $6^{\text {th }}$ month of the study, volunteers at the Boys and Girls Club (BGC) made another push to spark members' interest in the free violin lessons offered at the center. Over the two-year period that we had been at the BGC, enrollment in these lessons tended to range between 2-5 participants, though the BGC serviced daily populations upwards of 200 youth. Despite the advertisements, enrollment in these lessons initially remained low-only three $B G C$ members - and those that did enroll highlighted the upper socioeconomic class at the BGC. Participants in the Rock Band Club were able to see the volunteers and those enrolled in the lessons bring the instruments and set up for practice. Within the second week of violin lessons, participants in the Rock Band Club signed up for the remaining 12 openings and, for the first time at the BGC, a waitlist had to be created. When asked why he signed up, 11-year-old Deshawn, an African American male who joined the Rock Band Club because of his interest in videogaming, said, "I want to play guitar, and if I can do this [mimicking playing violin], then I can do this [mimicking playing the guitar]."

Rhythmic videogames - virtual representations of rock music performance and practice-are some of the top-selling games of the decade. Guitar Hero, a game in which players use a guitar-shaped game controller to simulate playing numerous rock songs, generated revenues of more than one billion dollars in the United States within a record-setting 26 months of its release and held the alltime record for highest annual gross sales in 2007 (Quillen 2008). Similarly, the Rock Band franchise-which extends the performance opportunities to four simultaneous players, each potentially playing different instruments and parts - is now pushing over two billion dollars in sales, becoming one of the most lucrative media franchises of the new millennium and a cornerstone gaming experience for millions of today's youth. The extent of this wide-scale adoption is ripe for further examination of the presence and extent of music learning present in these videogames. This exploration is especially relevant for at-risk youth who have limited exposure to the performing arts but have greater access to videogame consoles (PEW 2008).

While other academic domains, like social studies (Squire \& Barab 2004) and science (Steinkuehler 2006), have been explored in the context of games, the visual and performing arts have been an understudied area of research, leaving open questions about whether and to what extent the arts can be learned in today's videogaming environments. While skeptics might argue that rhythmic videogames only enable one to develop skills specific to videogames, not to general musicianship, anecdotes like those in the vignette above stand in stark 
contrast to these critiques and open the door to the possibility that games like Rock Band may be helping youth make connections between game play and the reading and performance of music. In 2008, a research project commissioned by YouthMusic found that up to 2.5 million youth in the UK were inspired to take up real instruments after playing rhythmic videogames (Missingham 2007). Moreover, surveys like the Guitar Center Survey have linked sales of Guitar Hero to later customer sales of acoustic and electric guitars, creating further rationale for these connections (Quillen 2008). Few games studies have demonstrated these kinds of connections between game play and real-life outcomes.

We argue that rhythmic videogames like Rock Band bear a good deal of resemblance to the "real thing" and may even be more well-suited for encouraging novices to practice difficult passages, as well as learn musical material that is challenging to comprehend using more traditional means of instruction. To further investigate the possibility of whether youth could be learning anything about traditional musicianship during game play, we collaborated with professional composers and music educators to analyze the musical concepts embedded within Rock Band as well as to triangulate these findings with observations of 26 youth as they engaged in Rock Band play at a local Boys and Girls Club over a period of nine months. Using a sociocultural lens, we sought to better understand the potential relationship between the players' participation in the Rock Band environment and measures of formal (outof-game) musicianship - for example, reading, writing, and echoing music written in standard music notation (key forms of literacy in the music education curriculum [Keene 1982]). Players' ability to internalize the Rock Band on-screen notation and use this as a tool to interpret classical (on a five-line staff) notation is explored through the traditional music assessments administered to the youth in our study. Collectively, our findings suggest that certain design features and the ways in which music is represented in Rock Band provides players with a "doorway in" to more formal music practices through heightening players' interest and abilities in music (Wiggins 2009). We call this the Nirvana Effect, in reference to the popularized notions of the "Mozart Effect" that claimed a connection between early childhood exposure to classical music and positive mental development (Rauscher, Shaw and Ky 1993; Thompson, Schellenberg and Husain 1991; Campbell 1997). The Nirvana Effect, instead, describes how playing rock music in contemporary game genres can have important learning benefits for the learning of the fundamental mechanisms of music. We discuss the implications of these findings and the general lessons for educators and researchers interested in connecting out-of-school learning to the goals of the classroom.

In this paper, we present a textual analysis of Rock Band's music notation, calling attention to the musical concepts embedded in the game's interface design. Aided by professional composers and musicians, we map how closely aligned the videogame's notation system is to that of traditional notation, an element often overlooked in the popular discussion around the game's simplified instrument 
controllers. In particular, we focus on the rhythmic concepts that the game teaches. While this analysis leaves little doubt that the game's notation system is well aligned with standard notation, the question then becomes whether novices playing the game can then use the game as a way of understanding music and music notation more generally. To further examine these ideas, we turn in the second half of the paper to a group of youth at the local Boys and Girls Club and track their Rock Band play as well as measure their performance on more traditional musicianship tasks.

\section{THE NATURE OF IN-GAME MUSIC LEARNING}

Many of the critiques against the possibility of in-game music learning concentrate on single aspects of the musical experience-most often the mechanics of the game controller versus a real guitar (Masters 2009; Fletcher 2009) - failing to take into account that players engaged in rhythmic games actually learn to read a fairly complex in-game notational system that embodies a lot of rich musical concepts concerning how music is put together and performed. When an individual purchases a guitar after spending an extended period playing Rock Band, the knowledge they appropriate from the game to the real world is less rooted in any instrumental facility they've developed (e.g., which frets to press for a $\mathrm{C}$ major chord), than in the foundational concepts of music upon which the player builds their understandings of how music "works." The distinction between instrumental facility and knowledge of music fundamentals is also voiced in the music education and popular musicology literature by pioneers in the exploration of youths' informal music practices (Green 2002/2005/2008; Campbell, 1995; Clements 2008). In this research, scholars cite examples of youth developing their aural, improvisatory, compositional and/or theoretical intuitions, even haphazardly, through immersion in peer-led musical activities (in the absence of formal instruction) (Green 2005; Abril 2008; Lum, 2009). An element that Lucy Green (2002/2005/2008) identifies as the prime source of informal music learning is youths' emulation of recordings, emphasizing the connection between the listening experience and the act of performance. In traditional music education curricula, the listening experience and the act of performance are often kept separate by a focus on how music is notated, with the memorization of note names, key signatures and tempo markings being a central focus (Colwell and Anderson, 2002). Upon learning how music is written down, most music students are then set down a path of mastering their instrument through repetition of difficult passages, a practice that emphasizes the eye over the ear and renders aural emulation near-obsolete. The perpetuation of "by ear" (i.e., without learning to read or write music notation) learning for pop/rock or folk musicians and not for concert/classical musicians is largely due to inherent differences in those musical genres, which includes, but is not limited to, considerations of ensemble size, availability of recordings and the requirements for playing work that has never been performed before. But even in cases where applicable recordings are readily available for formally educated (in music notation) students, a mantra still 
exists among many music educators that beginning students should essentially "learn the notes first, then make it musical" -in effect designating the act of critical listening (i.e., to a master's performance) as a value-added activity to be supplemented, when possible, to the primary goal of mechanical facility (i.e., pressing the right key and the right time).

And, yet, the environment in rhythmic videogames presents the aural and the notational elements of the music as intertwined by linking recordings of a master musician's performance to a scrolling notational system. This, in effect, presents the best of both worlds, with musicians' understandings potentially augmented by connections they can make between sound and visual representations. Even those trained in formal notational systems report hearing new elements in the music through this activity than from score-reading or listening, alone. This bridging of the gap between the reading and performing of music for both the novice and even the classically trained musician, bringing musical literacy to a wider audience, is one of Rock Band's most substantial contributions to the field of music. Prior studies have attempted to address the failures of the music notational system to reflect what is heard in the musical experience (Bamberger 2003) and to attract musicians trained to learn music by ear. Games like Rock Band allow the player to fully immerse him or herself in a musical, gaming experience, bypassing the introductory tedium in traditional music study of learning about five-line notation and the mechanics of an instrument before making any music. And, yet, despite the curtailed introduction to musical concepts, players of Rock Band report experiencing an immersion in music, one that encourages them to follow and "read ahead" in a musical score as well as enable them to listen to music differently; they pick apart different things in the song (i.e., bass, melody, rhythms, structure) thus elevating the gaming experience to a level steeped in music learning (Miller 2009). It can be argued that the non-musician would be unlikely to pick out certain music concepts or features just by passive listening and responding to questions about a piece of music. However, take that same non-musician and have them play Rock Band and their passive listening becomes active; they immerse themselves in an activity and these concepts and features arise due to their participation.

A key component of this learning lies in the intuitiveness of the game's onscreen notation. Rock Band utilizes a combined form of guitar tablature and a modified MIDI notation that translates notes into vertical rectangular blocks that pass over a horizontal "finish line" using a logic system similar to that of a player piano scroll. In this system, the duration of a note is represented by the length of the block and, in the case of guitar play, the horizontal placement on the screen parallels the desired placement of the player's finger on one of five possible "strings" (i.e., colored buttons) on the guitar's neck. By contrast, traditional music notation is a highly codified language, requiring the musician to recognize a multitude of symbols that visually have little direct relationship to the sounds they represent. 
The simplified instrument interfaces, though a focus of criticism from naysayers, is a key enabler of the notation system's internalization. The game controllers are simplified to various degrees-participants singing into the microphone can vary the amount of forgiveness that the game applies to their pitch inaccuracies when singing; the drum set is smaller, and (at the time of this study) the instruments that are set up at differing heights on a real drum kit are all placed side by side and condensed into only four evenly spaced pads (excluding the kick drum pedal, played with the foot); the guitar controller, the most simplified of the group, condenses the 23 frets (horizontal partitions on the neck of the instrument that separate one pitch from the next) and six strings into a single line of five buttons (with an additional five buttons toward the center of the instrument for the more expert levels). This means that the possible hand positions on a guitar are condensed from 138 to five, and that's not even counting the multitude of possible combinations when more than one pitch is being played at a time. The lack of nuance in the controller version of these instruments call attention to the fact that learning to play their real-life counterparts through game play is perhaps beside the immediate point of the game, as mechanical complexity could potentially hinder a player's ability to participate and dedicate energies toward the mastery of the notational system's logic. We argue that physical limitations of the controllers are part of an effort to dedicate more of the players' mental energies toward the notation system, as well as provide incentives (i.e., heightened musical experiences via low-hanging technical proficiencies) for players to continue playing.

Furthermore, Rock Band provides an additional learning scaffold by aligning intuitive notation symbols with prerecorded instrument tracks, in addition to providing formative feedback (the "note" bars on the screen fail to illuminate and your instrument temporarily drops out of the song when you hit the wrong keys) that lets players know if their actions correspond with the notation on the screen. This dynamic feedback is rarely afforded to musicians outside of game play, who must be told by someone with more experience (usually a parent, bandmate or teacher) if what they played was contrary to what was written on the page. Furthermore, the 1:1 relationship between the length and number of symbols on the screen, the physical act of manipulating one's controller/instrument in time with the symbols, and the accompanying musical sounds from the game when the act is executed properly reinforces the symbiotic relationship between a notation system and sound, sensitizing players to the multiple parameters required to effectively represent music in a written form. It is our contention that the music concepts central to the comprehension of traditionally notated music are represented in rhythmic games' notation system, including models of metric hierarchy, subdivision, measurement and pattern identification, which serve as a novice-friendly method whose lessons can be applied to more traditional forms of notation, affording beginning learners a 'doorway in' to more formal practices (Wiggins 2009). 


\section{GUIDING THEORETICAL FRAMEWORK}

Building on prior studies that have used a sociocultural view of learning in music (e.g., Green 2008; Clements 2008; Campbell 1995), we argue that Rock Band acts as a tool that mediates learning in music through its representation of musical ideas. Moreover, a sociocultural view of learning supports that individuals learn through interactions with tools that mediate their experiences, allowing individuals to do more than what they could on their own (Vygotsky 1978; Wertsch 1985). In the case of Rock Band, the game allows players to perform music through the simulated game play regardless of their instrumental facility, which is in large part through the game's representation of music. The Rock Band music notation is an example of what scholars refer to as a visual representation, a type of tool that mediates the interaction between the individual and goal of an activity (in this case, music performance) by supporting the storage, organization, comparison, and movement of complex information (Latour 1988). Over time, external tools and representations become internalized and abstracted, becoming a psychological tool. As the game's notation system moves from an interpersonal plane to an intrapersonal plane, it becomes a psychological tool, which allows an individual to recognize that other representations (i.e., other musical notation systems like traditional notation) are labeling the same musical phenomena in different but related ways (Cole and Engeström 1993; Cazden 1981). We argue that the means in which Rock Band players internalize the game's representations of music can transform the way that they see different forms of music notation and hear music, in general. More specifically, this theory supports the idea that users' mastery of Rock Band's alternative musical notation system can support learning of classical (5-line) notation and fundamental music concepts, which is the subject of investigation within this paper.

To further test these ideas, we turn to a group of youth at a local Boys and Girls Club and examine the relationships between extended Rock Band play and performance on traditional music education tasks like sight-reading, transcribing, and repeating simple rhythms represented in traditional notation. In K-12 settings, children are required as early as kindergarten to echo rhythmic patterns by vocalization, clapping their hands, or playing on an instrument (Education World 2008). At the core of both rhythmic videogames and school-based music education is rhythmic learning and notating rhythm. Given the dearth of research within the field of music education that inform whether rhythmic videogames could be used to support music learning, what's needed is a better understanding of whether, and to what extent, youth can use non-traditional representations of music to connect to more traditional musical notation systems and ideas.

\section{RESEARCH QUESTIONS}

This study investigated the following two questions:

- Does extended Rock Band play mediate player's learning of the game's representation of music? 
- Is there any evidence that extended Rock Band play mediates participation in traditional music activities, such as sight-reading, transcription or echoing tasks, using traditional notation systems?

\section{METHODOLOGY}

\section{Field Site: The Boys and Girls Club}

This research took place from September 2008 through May 2009 in the after-school hours at a local Boys and Girls Club (BGC) (Hirsch, 2005) located in a mid-sized Midwestern city. The Club services between 180-200 members each day (54\% male, $46 \%$ female) between the ages of 5 and 18 . At the time of this study, approximately $50 \%$ of the BGC members came from single parent households. The socio-economic status was working- to lower-middle class, with the majority of parents applying for financial assistance to cover the BGC's \$20 annual fees.

Monday through Friday, between 8am and 3:45pm, all is quiet at the $B G C$, save for the faint music coming from the cleaning crew's portable boom box. The full size gym upstairs, the computer lab, music room, games room, and library that reside downstairs are all empty. However, at 3:45pm the busses carrying kids from across the local school district pull up, decimating the earlier calm with the squeaking shoes and chattering voices of youth as they grasp for pool cues, basketballs, chairs in the computer lab, and a quiet space to finish homework in the library.

Over the loudspeaker at the Club, a voice calls out, "Lisa, it is time for your recorder lesson." Lisa grabs her recorder and heads off to a secluded room to get her once-per-week, free recorder lesson. There is not so much as an inquiry or curious look from the other club members about what Lisa is doing. After her lesson, Lisa returns to her previous activity, which is not music-related.

Such was the state of the music lessons offered by volunteers at the BGC at the start of our study, most often on the violin or recorder. Though free and available to anyone at the BGC, very few members took advantage of the opportunities for formal music instruction. Lessons involving the recorder involved one and sometimes two students in a small room with little privacy. At the start of our observations, only five youth - four girls and one boy - had signed up for these lessons. The majority of these participants were Caucasian $(80 \%)$ and from middle to upper-middle class homes.

\section{Rock Band at the Boys and Girls Club}

Having observed the BGC's music culture since the fall of 2007, we introduced a "Rock Band Club" in September 2008 in an effort to uncover if music learning was a possible outcome from youth's engagement in the game 
(see Figure 4). The Rock Band Club convened two to three times per week in a small room off the gym for a period of nine months. An Xbox 360 console, the Rock Band game and peripherals and an adult was all it took to transform the room into the Rock Band Club. The music blaring from the television and the singing and clapping from the club members were enough drown out the stampeding sounds of the neighboring basketball or dodge ball games and attract crowds that would pack into the tiny room. On a weekly basis, about 40 - 50 youth (about a quarter of the total Boys and Girls Club population) rotated through the Rock Band Club.

On a game-by-game basis, players rotated between instruments to allow everyone in the room at least one turn (referred from now on as a session) each afternoon. As a result, each player was allowed to complete one song and then had to become a member of the audience and wait for the next opportunity for game play. Players had their choice of which instruments to play but occasionally the researcher assigned youth to the drums to make sure that participants were trained consistently.

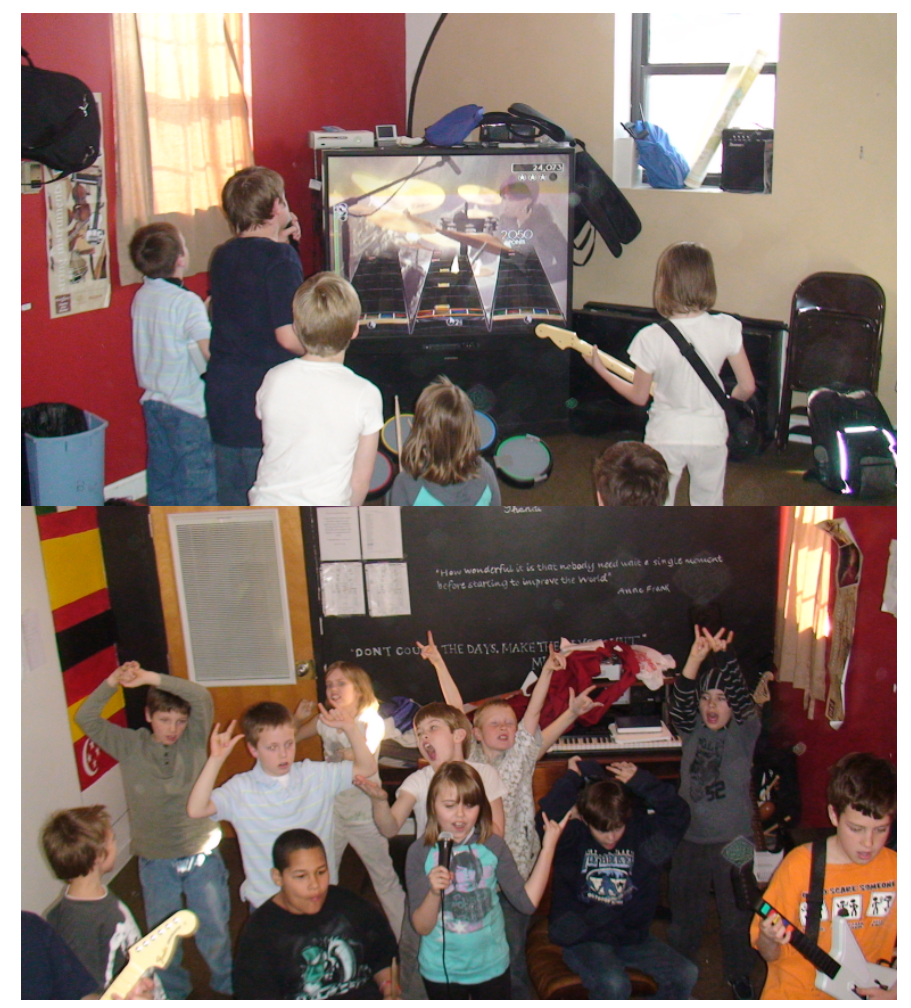

Figure 4: Images of youth during the Rock Band Club.

\section{Participants}

The focus of the current study was on a group of 26 participants (23 male and 3 female) that participated both in the Rock Band Club as well as participated at least once in our traditional music notation tasks. There were three fixed 
windows for enrollment in the current research study. The initial group $(\mathrm{n}=9)$ was recruited August through September 2008 - and logged an average of 42 sessions. The second round of recruitment came January through February 2009 and participants $(\mathrm{n}=10)$ logged an average of 13 sessions. The final group $(\mathrm{n}=7)$ was recruited at the close of the study-May 2009-and participated in no Rock Band sessions. All participants had little to no experience with rhythmic games at the start of the study. The average age for all three groups was between 10 and 11 years (fourth through fifth grade). No significant differences existed between groups in terms of gender, race, ethnicity, or other factors, such as interest in music and/or rhythmic videogames.

\section{Data Sources and Analysis}

This study used a mixed-methods approach to data collection. Data was drawn from participant observations recorded in the form of field notes, and from surveys, videotaped observations, in-game performance statistics, and a series of traditional music assessments (including sight-reading, transcription, and echoing tasks), which are further detailed below.

\section{Survey Data}

At the start of the study, participants completed a survey that gathered demographic information, videogame playing habits, favorite types of video games, music experience at home and at school, and interest in music activities. Questions included, "Do you have a musical instrument at home?", "How many times per week do you play video games?", and, "If you could play any instrument, what would it be?" Survey data was quantitatively analyzed using descriptive and summary statistics.

\section{Participant Observations}

As field note records of musical activities at the BGC were on file from observations that took place prior to the formation of Rock Band Club, we went through and tagged field note excerpts that related to participants' interest in the Rock Band Club and traditional music lessons, looking for shifts in the BGC culture over time. We also tracked individual cases over the period of the study. We highlight one particular club member, Carrie, as a representative sample of the participants. Carrie was an enthusiastic nine-year-old girl who, like most club members in our study, bounced from one activity to the next searching for a place with which to identify.

\section{Videotaped Observations}

A video camera was placed in the corner of the room that captured both the players and the audience during game play. After each day of observation, videos were logged for general record keeping. Log files noted who was playing, which song, and which instrument was played. These logs allowed us to generate the number of sessions by instrument for each participant. Video logs were 
quantitatively analyzed using descriptive and summary statistics.

\section{Traditional Music Assessment}

To investigate the relationship between the in-game notation system to other formal notational systems, researchers, aided by local music educators, developed a series of (1) sight-reading, (2) transcription, and (3) echoing tasks. To do this, we pulled measures from the local music textbooks based on the Kodály Method (MacMillan/MacGraw Hill 2005) that were age-appropriate and followed $\mathrm{K}-5$ standards for music. This assessment was administered to all participants $(\mathrm{N}=$ 26) at the close of the study.

The traditional music assessments had two levels for each of the exercises in sight-reading, transcription, and echoing (a total of six items). Level 1 exercises consisted of rhythms that contained only half, quarter, and/or eighth notes and/or rests, while Level 2 contained those notes from Level 1 with the addition of sixteenth notes and rests. Levels 1 and 2 consisted of four, one-measure exercises (see Figure 5).

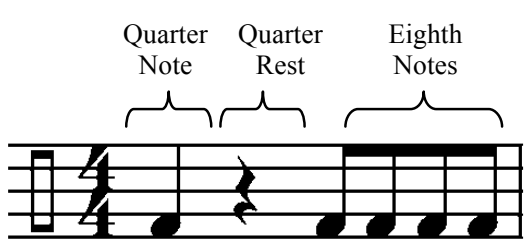

Level 1-Exercise 3 (excerpt)

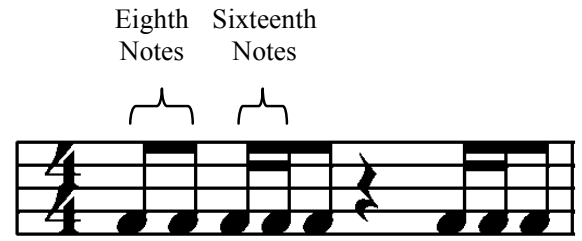

Level 2-Exercise 3 (excerpt)

Figure 5. Sample excerpts from traditional music assessment (Levels 1 and 2)

To perform the traditional music assessment, participants used a Rock Band drum controller connected to an iMac computer loaded with the MIDI sequencing program, GarageBand, which kept an electronic record of the session. For the echoing task, participants heard a pre-recorded exercise and were asked to repeat the rhythm on the drum controller. For the reading task, participants were asked to sight-read (play music that they've never heard before) a two-measure rhythm in traditional notation. Finally, participants performed a transcription task, where they were asked to notate music that they heard on a recording using a notational system of their choice. They were not given any explicit information on how to notate music from the researcher.

Data sources for the three tasks were scored and averaged to create a composite score for the traditional music assessment. Using the MIDI data from the echoing and sight-reading tasks, outside experts in music compared the original example to the response recorded during the assessment. For both echoing and sight-reading tasks, a scoring system was developed using a norm criterion reference; the data was scored from 0 (lowest) to 5 (highest) on player performance on both tempo and accuracy (e.g., playing the right durations at the right time). For the transcription exercises, outside experts employed a similar 
scoring system based on three categories, including the use of (1) symbols related to the rhythm in question; (2) the correct number of notes/symbols; and (3) grouping together note entities in ways that had high fidelity to the rhythm being heard. Scores also ranged from 0 (lowest) to 5 (highest) for transcription. All data was doubly coded and inter-rater reliability between the two coders was $93 \%$. Any discrepancies in coding were discussed and resolved before proceeding further with analysis.

Participants each received six separate scores, two (i.e., one for Level 1 and 2 tasks) each for the sight-reading, transcription, and echoing task. An average of the six items in the traditional music assessment was calculated for each of the participants and used as a measure of the participant's ability to interpret traditional notation. Further, we sought to investigate the relationship between the number of Rock Band sessions and youths' scores on the traditional music assessment using a simple univariate regression (i.e., a Pearson's productmoment correlation coefficient) to determine whether a significant correlation existed between our two variables of interest.

\section{FINDINGS}

Informed by an analysis from a professional composer and musician (our third author), our findings first explore the extent to which musical concepts are present in Rock Band. This textual analysis pays special attention to elements of rhythm, and discusses the fidelity of the game's representational system in representing aspects of the listening experience as it compares to traditional notation. Our textual analysis is then followed by findings from our Rock Band implementation at the Boys and Girls Club.

\section{The Rock Band Notational System: A Textual Analysis}

Let us further examine the ways in which the audio-visual musical representation in Rock Band serves to illuminate authentic music concepts. While there are numerous concepts that can be learned through the game, we are focusing our analysis here on a selection of concepts pertaining to the rhythmic domains - metric hierarchy, rhythmic measurement and subdivision, and the symbolic representation of sound and silence - as well as some brief discussion of pitch contour, instrumentation and texture. Of these, the rhythmic concepts are central to our analysis because of the directness of their application to early K-12 music education standards, as well as because their in-game representations are less scaffolded than their pitch-based counterparts.

\section{Metric Hierarchy}

Similar to classical musicians' use of a metronome to make sure that they play their notes at the right time, Rock Band engrains in its players the importance of identifying meter, recognizing repeated patterns, and playing in consistent synchronization with other players. The grid of thick and thin lines that splay across the guitar and drum parts in Rock Band instill in the player the song's 
meter - the structure of notes in a regular pattern of strong and weak beats (see Figure 1$)^{1}$. Traditional notation uses vertical lines to partition these patterns into units of (most commonly) 2-4 beats, called measures ${ }^{2}$. However, traditional notation does not visually differentiate between strong and weak beats - this is something that has to be learned separately. While Rock Band delineates meter in a similar fashion, it illuminates the hierarchical system of strong and weak beats by moving the note-bars onto a grid of thick horizontal lines (to represent the first beat in a measure) and thin ones (to represent the weak beat[s] following it). One can see in Rock Band that the most simultaneous attacks across the ensemble, and even within the drum part alone, fall on these strong lines, calling attention to how this concept of metric hierarchy is transmitted both visually and aurally (see Figure 1).

Metric hierarchy is an essential aspect of music understanding as it provides the framework in which unique groups of patterns are organized. So that the listener/player does not hear the chorus to the Rolling Stones' "Satisfaction" simply as a group of four syllables ("I can't get no...") with an indeterminate amount of space before another group of four syllables finishes the thought ("...satisfaction"), Rock Band puts in place a concept of metric hierarchy that helps the listener/player to quantify the musical distance between the two groups (four beats), as well as illuminate larger repeating patterns at work in the passage (the whole pattern takes four measures to complete, which repeats four times). Listening to the larger metric structures at work helps listeners to string disconnected groups of notes into larger, intuitive chunks in an echo task, as well as inform musicians where to place notes in a measure in a written transcription task.

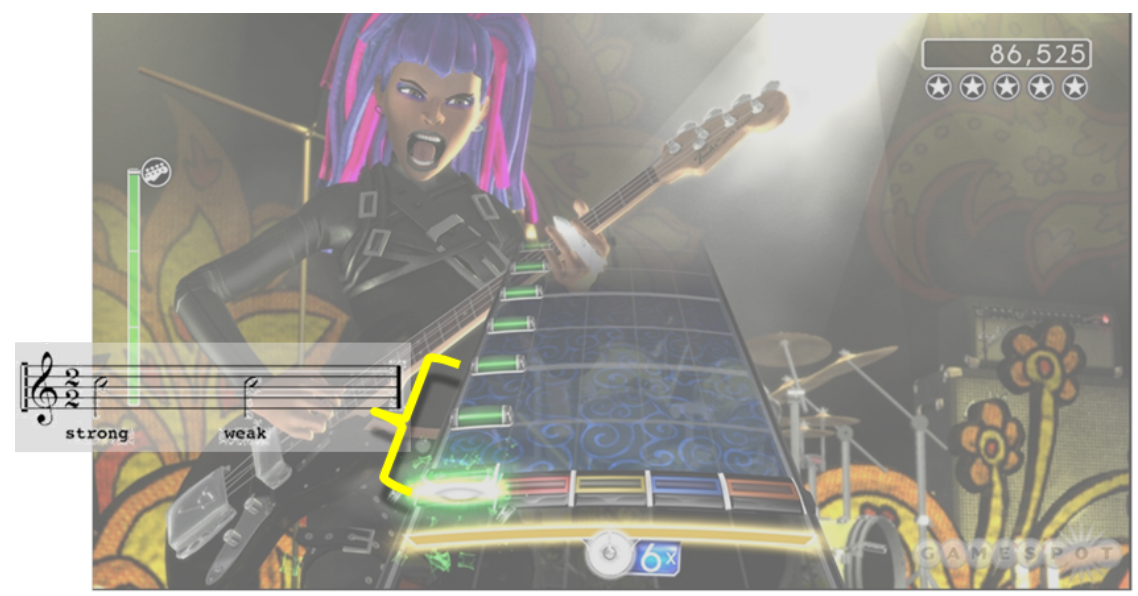

Figure 1: The first beat of any measure is stronger than the ones that follow, an attribute visually apparent in Rock Band's thick/thin horizontal line notation but not in a traditional notation system.

\footnotetext{
${ }^{1}$ One can especially hear meter in any ballroom dance, which emphasizes the strong beats in order to facilitate the appropriate steps. A waltz, for example, regularly puts stress on the first beat in each group of three (STRONG-weak-weak, STRONG-weak-weak, etc.).

${ }^{2}$ A time signature is also used in traditional notation to clarify how many beats exist in each measure, and what note value (quarter-note, half-note, etc.) is considered one beat.
} 


\section{Semiotics of Metric Subdivision/Rhythmic Measurement}

If recognizing how many beats there are in a measure is a first step, being able to break down rhythmic patterns that take place within each measure is the next. Within each measure, note values - such as quarter-note, half-note, and whole note - tell you how long each note is to be held. A short or long sequence of these notes, especially when the patterns repeat in a specific way, becomes known as "a rhythm." If you tapped the Happy Birthday song on your lap without singing the pitches, you will have just performed the rhythms that make up the Happy Birthday song.

The concept of breaking down a measure into smaller beats or sub-beats (which is important even in a tune as simple as the Happy Birthday song) is called subdivision. Subdivision includes dividing a note evenly into smaller note durations, and, if necessary, dividing it again evenly into even smaller durations. Traditional notation reflects the halving of a given note by either adding a flag or beam, or at the larger levels, a stem or a filled-in notehead (see traditional notes, Figure 2). This method of assigning fraction names to a note (e.g., a $64^{\text {th }}$-note fills up $1 / 64$ of a whole measure) is thought by some to reinforce math learning, but the relationship between the sound and the symbol are purely abstract. The noteheads for a very short note and a very long note are, with few exceptions (e.g., grace notes), the same physical size, even though their durations (a matter of their "size" in time) are vastly different. This is not the case in rhythmic videogame notation, where the scrolling note symbols are as short or long as the corresponding sounds in the audio track, with the rate that the notes cross the "finish line" ensuring that all players read the notes at the right speed. This is ultimately a closer visual likeness to the sound the player actually makes.

Symbolic Representations of Sound and Silence

Another layer of notational complexity avoided by the Rock Band's scrolling notation is that of rests, symbols representing the silence between notes. These are an entirely different set of symbols for the learner of traditional notation to internalize, and something that can easily be represented by a space onscreen can translate into a complicated string of rest values on paper. In this regard, too, silence is visually more intuitively represented by emptiness (as in the case of Rock Band) than by the presence of symbols that bear no direct association to the aural phenomenon of silence (as in the case of traditional notation).

It is here, too, where the salience of Rock Band's communication of metric hierarchy is especially important_-instead of symbols floating freely in space, their spatial correspondence to a grid of thick and thin lines (i.e., measures and beats, respectively) allows players to accurately quantify sound and silence within their parts as the on-screen gridlines are manifestations of a pulse that is, in most cases, constantly felt in the music. This not only subtly encourages the player to connect the hearing and reading experience of performance but also drives the accuracy of execution - spotting patterns (and whether they appear to fall on or off the metric gridlines) in advance of their crossing the "finish line" at the bottom of the screen gives the player a clearer sense of what the music will sound like a 
couple seconds in advance, an important concept of "reading ahead" that musicians reading from traditional notation are encouraged to do in order to anticipate challenging passages and to make better directional sense of long phrases of notes.

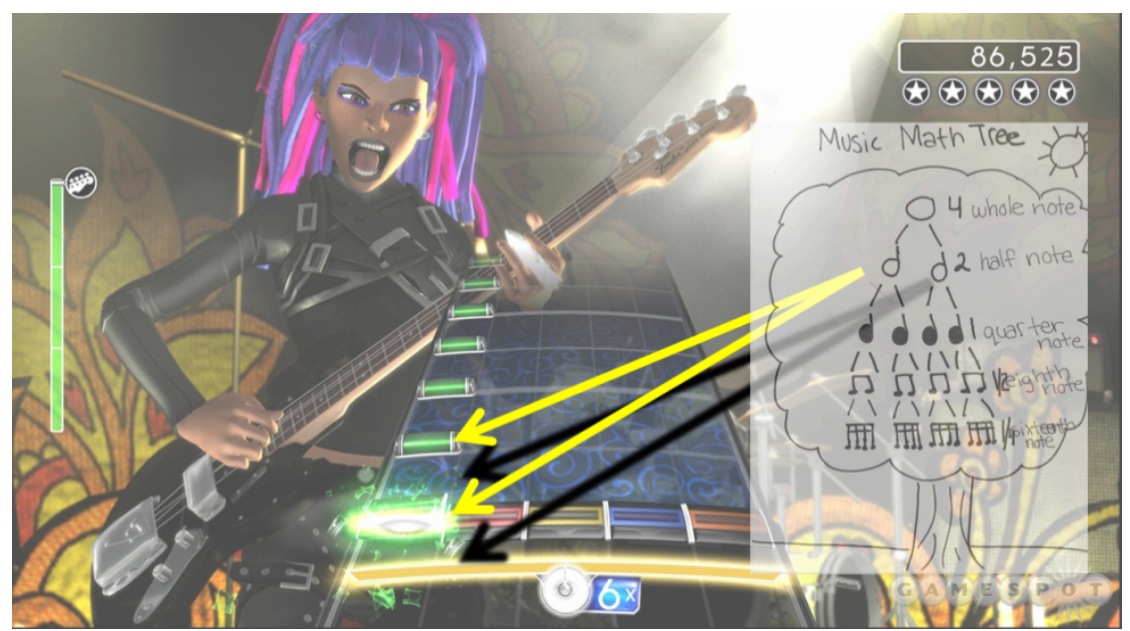

Figure 2: Traditional notated music shows the relationship between long note values and those a fraction of their length using a unique system of note-head styles and beams. Rock Band shows the subdivisions of a note through spatial means (e.g., a rhythm consisting of whole notes [one measure long] would fall exclusively on the thick horizontal lines on the screen, while one consisting of half-notes [each half the length of a whole note] is shown in Rock Band as falling equidistantly between the thick lines - a more striking representation of the mathematical relationship.)

It should be noted that the visual representation on the screen to the music that supposedly emanates from your virtual instrument becomes increasingly faithful as the player progresses from beginner to expert levels. At the expert level, all notes-including their durations and rhythms (excluding their exact pitches) - are perfectly transcribed from the original song playing in the game's audio track. At these higher echelons of game-play, the connection between audio and notation becomes most direct. Whereas at the beginning levels players are only tasked to hit buttons on the most structurally important aspects of each phrase (e.g., if the image in figure 3 was taken from beginner mode, the player might be hearing more notes from the recording in between the ones they're tasked to play), thus making the on-screen symbols seem to the player more like a series of event triggers and less like a notational system with direct relationship to the music heard.

In addition to the purely rhythmic concepts just discussed, the more advanced concepts of how multiple simultaneous parts can overlap and interact in a piece of music (an aspect relating to a piece's instrumentation and texture) and the concept of melodic contour are artfully presented in Rock Band.

Melodic Contour 
Even the gamer without any musical experience may observe that, when singing in Rock Band, the higher blocks on the grid correspond with the higher notes in the vocal track, and vice versa. The same phenomenon takes place for bassists and guitarists in the game, as well, where keys higher on the fret-board are used to play higher notes and vice versa. Tracing an invisible line that rises and falls with the ascent and descent of the blocks is something called melodic contour, the directional shape of a melody (see Figure 3). Recognition of melodic contour (whether the melody moves up or down, stepwise or by leap, etc.) is the cornerstone of being able to read unfamiliar music from sight, a concept that proves problematic for many even in college-level ear training courses.

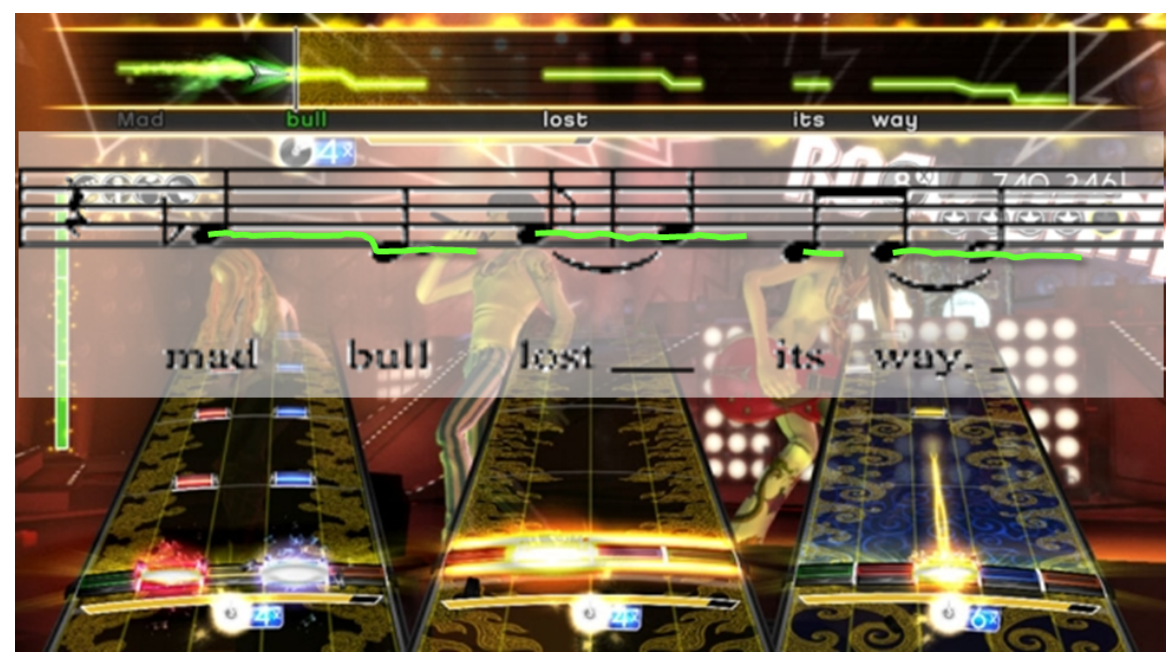

Figure 3. Depiction of how the melody represented in Rock Band maps onto classical notation.

\section{Instrumentation and Texture}

Among the more gratifying aspects of playing an instrument is the ability to play together with other instrumentalists, playing music more layered and full sounding than any one player could perform on their own. Whether multiple players are playing the same part simultaneously, or one is playing a more prominent part while the others act more as accompaniment, or perhaps all parts are different but equally important, these are all variations in a piece's texture. Rock Band was the first rhythmic game to support gamers' ability to play all instrumental lines in a single song simultaneously, introducing to musical novices the concept that the songs they hear on the radio are comprised of several different layers of musical activity. Perhaps, at first, gamers might not have the mindset to try to audibly discern which instrument is playing the most memorable licks in the song, or to break up the band's composite sound into distinct parts, but a quick glance at the screen in multiplay mode is enough to transmit that there are four independent parts that work in conjunction to make a unified sound. Players can additionally, by alternating instruments at first and eventually being able to listen to other parts while playing their own part, can come to understand something about texture and the various idiomatic roles in the ensemble, 
essentially reading music from a score - a notated version of all simultaneous parts in a piece of music - making that connection of the distinct contribution of each instrument more salient.

It is a fair assumption that players' tacit understandings of Rock Band's notation of the concepts presented here, as well as the others that are not included in the above discussion, improve as players level-up in the game. Players' success at the game, however, is not a fair measurement of their music learning in and of itself. Improving music learning in-game might be seen by some as nothing more than learning to play any other videogame, having little to do with music more literally. Therefore, the real test is whether players can apply their understandings of these concepts toward their learning of a new piece of music, or an instrument, outside of the game. Of direct concern to the field of music education, especially, is the extent to which Rock Band can assist youths' recognition and understanding of other notation systems.

\section{Portrait of the Participants}

Like most youth, the youth in this study were deeply interested in rock and pop music. Carrie, one of our case studies, was no exception. She was part of one of the first groups to engage with Rock Band in the Club's early stages. At the very start of the Rock Band Club, Carrie, a seemingly shy 8 year old girl with big, bright eyes and a quiet tone to her voice, asked "Can I bring in a mix CD I made?" Members of the Rock Band Club gathered expecting to hear the latest bubble-gum, top-40 contemporary pop music, and were somewhat shocked when bands like The Beatles, The Stray Cats, and Adam Ant burst from the speakers. More shocking still was her knowledge of each artist-from band members, to lyrics, to album covers. Carrie had always wanted to learn how to sing and play guitar, but had not yet experienced it.

Carrie, like the other youth in the study, paused on the first day of the Club to answer a short survey regarding their musical preference, video game playing habits, and musical experience at school and home. She informed us that she likes playing sports-themed video games everyday and that between her mom and dad's house there was a Nintendo Wii, Gameboy, Nintendo DS, and Sony XBox -- quite a bit of access to a varied number of gaming consoles, especially since Carrie's family wasn't particularly well-off. Like Carrie, all Rock Band Club members had at least one but an average of 2.5 gaming platforms (e.g., console, PC, or hand-held) per household. The three most popular types of games being (a) sports games (e.g., Madden), (b) action games (e.g., Star Wars), and (c) shooter games (e.g., Halo). Since Rock Band and Guitar Hero were still rather new to the market, it was unsurprising that Carrie and the other youth in our study had heard of Guitar Hero and Rock Band, but never played them. Furthermore, $75 \%$ of participants played video games (e.g., console, handhelds, or computer) more than twice a week with an average playing time of 3.3 hours per playing session. Approximately half (47.5\%) reported playing videogames every day. 
All Rock Band Club participants in fourth grade or above had been exposed to music through the district-wide music education curriculum in the public schools. $12.5 \%$ of Rock Band club participants were in third grade or below and reported no prior music performance experiences (beyond singing). Only $15 \%$ of the youth reported having had at least one private music lesson outside of school. However, all of the participants reported having an interest in learning to play an instrument and, when asked what type of instrument that would like to learn, $85 \%$ chose instruments in the typical rock-and-roll instrument realm (e.g., the drums, electric bass, and electric guitar).

\section{In-game Performance Measures}

Central to our understanding of the youths' in-game learning was the onscreen data that was captured from their sessions, assisted by the corresponding videos that captured the youth while engaging in the game. This data enabled us to see any connections between the youths' performance and the scaffolds in their environments that contributed to their learning. Returning to one of our second research objective, we were interested in the changes that took place over the course of players' engagement with Rock Band, seeking to document the participants' learning of the game's representation of music.

In several instances, youth struggled initially with the game. But, once they understood how the notation system worked and what the corresponding physical requirements were, they became quite fanatical about their sessions. We believe there to be a number of possible causes that could explain youths' continued perseverance in Rock Band, even in spite of these initial hurdles. Carrie is one of those cases:

Carrie, along with three other girls (Haley, Sheila, and Jacquelyn), was recruited in the first round of the study. The other girls were just slightly older than Carrie and wanted to start their own girl band in the game. In their first session, each member of this new band picked their instrument with Carrie picking the guitar. Once they picked their avatars and song-Weezer's "Say it Ain't So"--Carrie started to look uncomfortable. Once the song started, she missed the first note, causing the guitar on the audio track to make a squeaking sound. She stopped playing, with the look on her face growing even more unsure. She began to look around as if to get Haley's (a more experienced player) attention. While looking around and the song still playing, Carrie said "I'm not sure...". Haley, who was standing behind her, sat down nearby and began to verbally explain how to use the controller. Eventually, Haley paused the game and said "hold on...let me show her" and pointed out to Carrie where the guitar part was on the screen and how to hit the correct notes. Once they started up again, the band's collective score was too low and the virtual 
audience booed them off the stage. Carrie was visibly upset about how she did. They restarted and Haley and Carrie decided to switch between bass and guitar (bass is a bit easier because it has less notes). Carrie was still having no luck--her timing was off just enough not to register the note. They failed again. Carrie stood up and said, "I'm not feeling very comfortable with this..." (referring to the bass). She was encouraged to stick with it. Before they played a third time, Carrie tried to explain why she is having trouble: "I'm not sure where my place is?...I'm [also] not sure how to press them [the button on the controller]". Both Haley and Sara stepped in to give her some pointers, though this did not make much of a difference in Carrie's next attempt. Carrie's head held in her hands, her band picks a new song to help. As each song was selected, a small, familiar snippet is played; no movement from Carrie. But when "hey, ho, lets go!" blasted from the television, the opening refrain of the Ramone's "Blitzkrieg Bop", Carrie exclaimed with a large smile on her face "the Ramones...let's do that one!" Her band mates agreed and she asked to sing. Her quiet tone was replaced with an enthusiasm, a new identity. Their band got to the end of the song without being booed off the stage for the first time.

Few activities support continued engagement from struggling participants in the manner exemplified in the above example. Carrie's difficulty with the game, by her own testimony, was a combination of both coordination ("I'm not sure how to press [the buttons]") and conceptualization of the notation system ("I'm not sure where my place is"). Neither of these issues were ones that could be rectified immediately, despite moving between instruments. And, yet, the band could keep playing when Carrie encountered a song she already knew, thus exempting her from having to figure out the notation system (she most likely had the melody memorized from prior exposure) or, by switching to vocals, the controllers. Far from being an "easy way out" from having to learn the material, this flexibility was a means in which to "stay in"--continuing to engage in the game. Having multiple ways to participate and succeed also provided her with more opportunities to observe how the other instruments' notational system behaved in the following sessions, helping her to become more comfortable with the notational concepts that gave her trouble at first. This was a common theme across several participants' learning: their internalization of the songs and notational system was assisted through the Rock Band club's culture of continuous immersion--where club members in the audience would indirectly rehearse each tune by clapping, dancing, playing air drums and guitar, and singing without the mechanics of the instrument acting as a barrier to their participation in the music. 
After a few weeks, Carrie wanted to try the drums, a controller that had, like the guitar, initially caused her difficulty. She sat down and started playing Garbage's "I Think I'm Paranoid." Much like her first time on the drums, her arms were very rigid and uncoordinated. Though she loosened up as the song progressed, her performance bar was too low and the band failed the song. Stephanie, who had been playing with her, had leaned down and patted her on the back and said, "c'mon Carrie, do your best". She was asked if she wanted to do it again. She said yes, but she wanted to try "Say It Ain't So", a song that she was very familiar with. When they began the song, Carrie was visibly looser when playing. She progressed through the entire song without failing. Once the song ended, both Stephanie, who was singing, and Brian, who was waiting his turn to play, both congratulated Carrie and patted her on the back. Carrie's score and percentage of correct 'notes' hit was displayed and cheers for Carrie erupted. She continued most of her time on vocals, but every now and then would switch to drums or bass. Over a short two-week period, Carrie's failures - at first three, which are the maximum, allowed in game-became two failures, then one, and eventually, she was playing entire songs without failure and moving to the other instruments. From that point on, everyone knew where to find Carrie. When her mom picked her up, there was no more looking around for her: she knew she was in the Rock Band Club.

The essential elements of Carrie's case are her continued involvement and her eventual, and from then on, consistent improvement at the game. Tracking this across the Rock Band Club participants, we graph below the players that have had 40 sessions or more their first and 40th playing of one of the most popular songs, Weezer's "Say it Ain't So" (see Figure 6). Like Carrie, most players initially struggled in their first attempts at the game, their scores eventually bottoming out around $30 \%-50 \%$ of the way through the song. By contrast, during the 40th game play, players' performance meter reached $100 \%$--despite continued struggles in the song's opening (i.e., this is a difficult passage)--indicating that they didn't miss any notes in certain sections, and with only periodic drops beneath $100 \%$ in the more difficult passages later in the song before returning to the top of the performance meter. Large-scale repetitions in the music also reveal a type of in-game learning that took place not only between the 1st and 40th plays but within each session as well, where repeated elements of the tune were executed with greater accuracy each time they occurred in a single session (e.g., the average performance meter increased across the three iterations of the "chorus" throughout the game, while the drop in performance for each "verse" decreased, albeit slightly, upon each of the three iterations.) These differences demonstrate that participants are steadily improving in their game play within each attempt and upon repeated attempts, demonstrating in-game learning. 


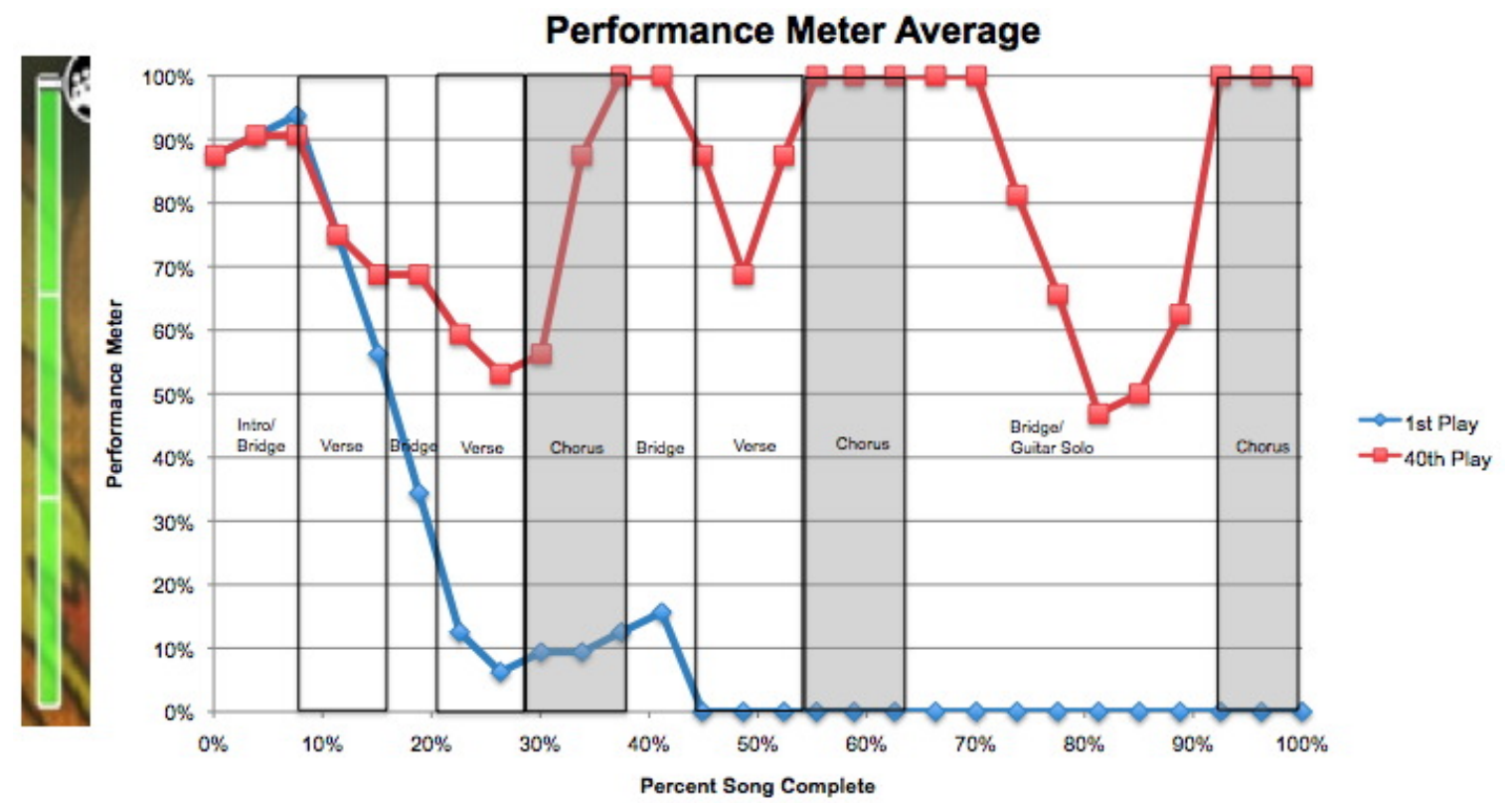

Figure 6. In-game performance meter measurements, comparing players' 1 st and 40th times playing Rock Band

\section{Results of Traditional Music Assessments}

If the longitudinal tracking of youths' performance meters in the game measures their learning of Rock Band--a form of musical participation--the results of the traditional music assessments provide us with a glimpse into youths' ability to internalize Rock Band as a tool to relate to traditional representations of music like music depicted on a five line staff. The aforementioned sight-reading, transcription, and echoing tasks test youths' ability to organize and reproduce musical representations in written and aural form, and, being prominent assessment techniques in the traditional music education curriculum, are representative of a range of activities that are important to the reading, writing, and performing of music.

Writing tasks received three scores, ranging 0-5, for each of three dimensions of music representation: use of symbols, number of symbols used, and spatial properties. Scores were then averaged together for a total of 5 points possible. A score of zero meant that either the symbols or grouping of symbols was not present in their representation. For example, if a club member drew someone playing a drum, they would receive a score of "0". A score of " 3 " meant that there were symbols present but were not music related, were not grouped properly, or did not contain the correct number of symbols for that particular pattern. For example, a good number of participants used symbols like X's, O's, and lines to represent the pattern. Finally, a score of " 5 " showed that the symbols used were music related, were the correct amount given the pattern heard, and grouped properly. As can be seen in Table 1, Carrie scored a 5 on Level One and a 4 on Level Two across these dimensions. 
The second task involved listening and echoing short rhythms. The short pattern was played and members simply responded by repeating or echoing the rhythm. A group of expert musicians then listened to the result and scored it based on a scale from 0 to 5 . A score of $0-1$ meant that there was little to no engagement with the task. For example, a club member just begins to wildly hit the pads with no regard for the instructions they heard. A score of 2 meant that there was some structure, but it was not consistent. For example, the club member may start out trying to play the pattern, but seemingly gives up or just starts to play wildly on the drums. A score of 3 meant that experts were able to hear a structure being played but was not consistent with the pattern the club member heard. A score of 4 meant that the pattern was consistent with what the Club member heard but the tempo (speed) of the pattern was either to fast or to slow. A score of 5 meant the pattern and tempo matched the example heard. Carrie scored a 5 on Level One and a 3 on Level Two for this particular task (see Table 1).

During the sight-reading tasks, Club members were asked to read a short rhythmic pattern written in standard music notation and asked to play it. When the sheet music was placed in front of Carrie on the music stand, she seemed unsure of herself for the first time. She had noted, as did most other club members, that she didn't know how to read music very well, but knew some of the notes from her music class. She was assured that there was no right or wrong answer and that it was simply what she thought the pattern sounded like. Once she heard that, her confidence resumed. She looked intently at the short, one bar, rhythmic pattern for a few seconds and played each 'note' as she thought it would sound. It was choppy and not fluid, like the musical equivalent of sounding out a new word when first learning how to read. While it wasn't as fluid as the echo task, it still obtained a score of 4 on Level One and a 2 on Level Two (see Table $1)$.

As one of the founding members of the Rock Band club, Carrie did well above the mean on each of the three areas of the music assessment, particularly for the level one assessments (see Table 1). This is despite Carrie's relative age within the group (she was one of the youngest members in the Rock Band club) and the assessments target concepts appropriate to students two to three grade levels older than Carrie. The table below presents each of the three music assessment tasks, summarizes Carrie's response visually for the reader, provides an explanation of how her response was scored, as well as the score itself. Additionally, the group mean is provided to contrast Carrie's scores with that of all of the participants. We should note that among the whole sample, there was a large amount of variability in how the participants scored on their traditional music assessments (see Table 1). However, as the number of Rock Band sessions increased, the variability of the sample decreased, resulting in a significant correlation between the number of Rock Band sessions and the overall scores on the traditional music assessments (see Figure 7). 
Table 1 - Carrie's score on each task compared to group average

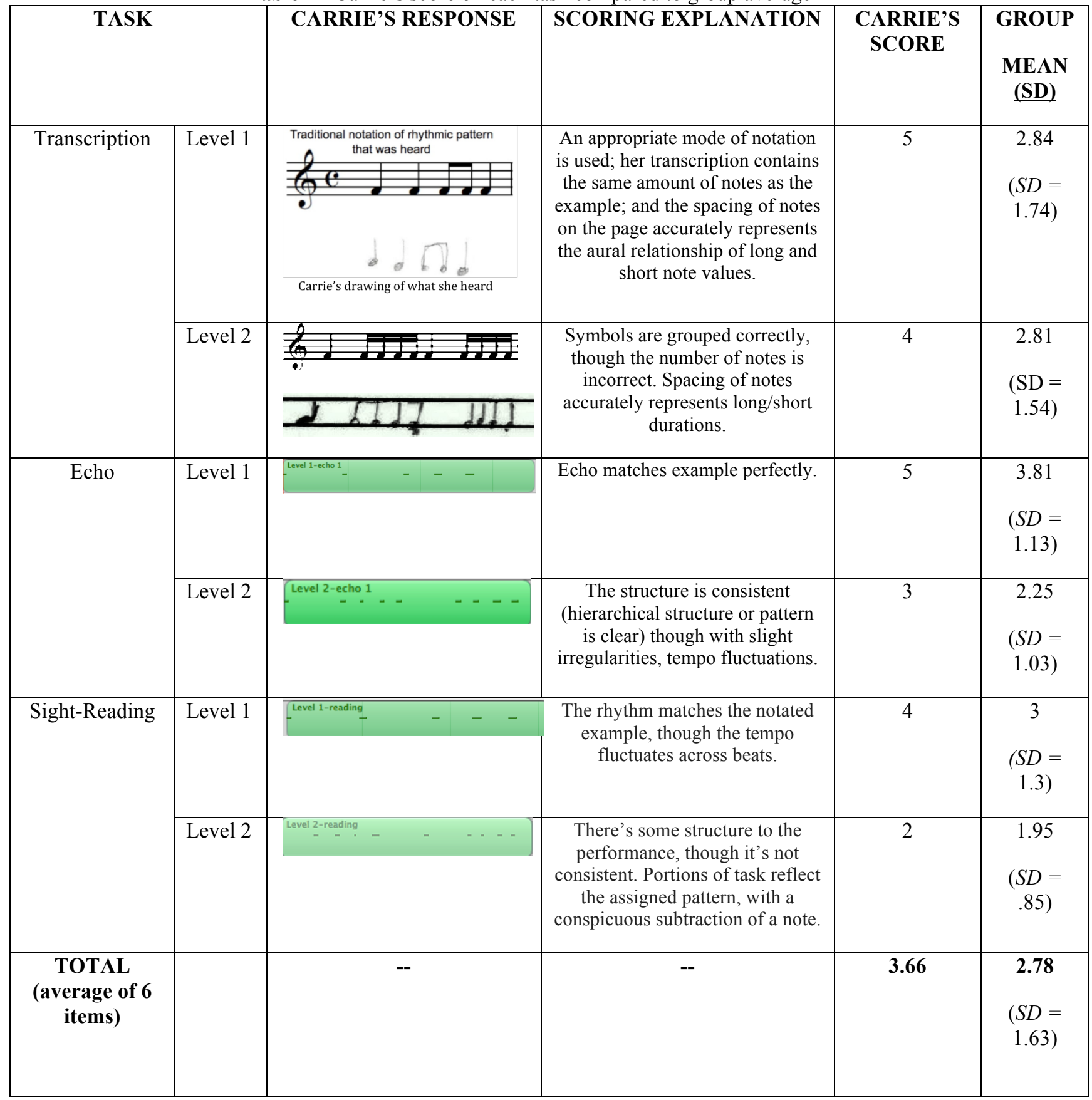

Carrie's scores on the traditional music assessment parallel that of her peers with extended Rock Band play. Looking across the participants, a large positive correlation was found between the number of youths' Rock Band sessions and the scores on traditional music tasks, $\mathrm{r}=.50, \mathrm{n}=22, \mathrm{p}<.01$ (two-tailed). In this case, the two variables share more than 50 per cent of their variance in common. In other words, the number of Rock Band sessions can explain more 
than 50 percent of the variance in traditional music assessment scores. In the following scatterplot of the data (see Figure 7), youth's scores on the traditional music assessment are plotted on the y-axis and the number of Rock Band sessions at the time of assessment is plotted on the x-axis. While not quite as robust statistically, similar correlation trends were found for both the easy and the hard tasks (i.e., Levels 1 and 2) as well as for the echo and transcription tasks. This large positive correlation between the number of Rock Band sessions and the scores on the music assessments, suggest that youth are using their understanding of Rock Band as a psychological tool to aid in their reading and writing of traditional notation.

Another interesting part of this story emerges when looking at the variance of the data both for participants with little to no (0) Rock Band sessions and contrast it with the variance of scores of those with 40 Rock Band sessions or more. As depicted in Figure 7, the variance among those youth that had no experience is quite large (a difference of nearly three points on the assessment measure). By contrast, as the number of Rock Band sessions goes up, the variance between youth diminishes to less than one point. This finding makes intuitive sense for the group with little to no experience with Rock Band. In any music class, you're likely to find a group of youth with a range of abilities and prior experience with traditional notation and other music practices (like echoing simple rhythms). Therefore, it's unsurprising that some youth would score high and others would score low at the start of any after-school club as there is bound to be a wide range of abilities and prior exposure to music among the group. However, it's more difficult explain the lack of variance in the sample as the number of Rock Band sessions increases. One explanation is that those youth with more extended play in Rock Band bear a greater amount of similarity in their traditional music abilities. Below we provide two alternative explanations for these findings, both of which support the paper's central thesis that youth are seeing similarities among the two notation systems, with one notation system mediating ability in the other. 


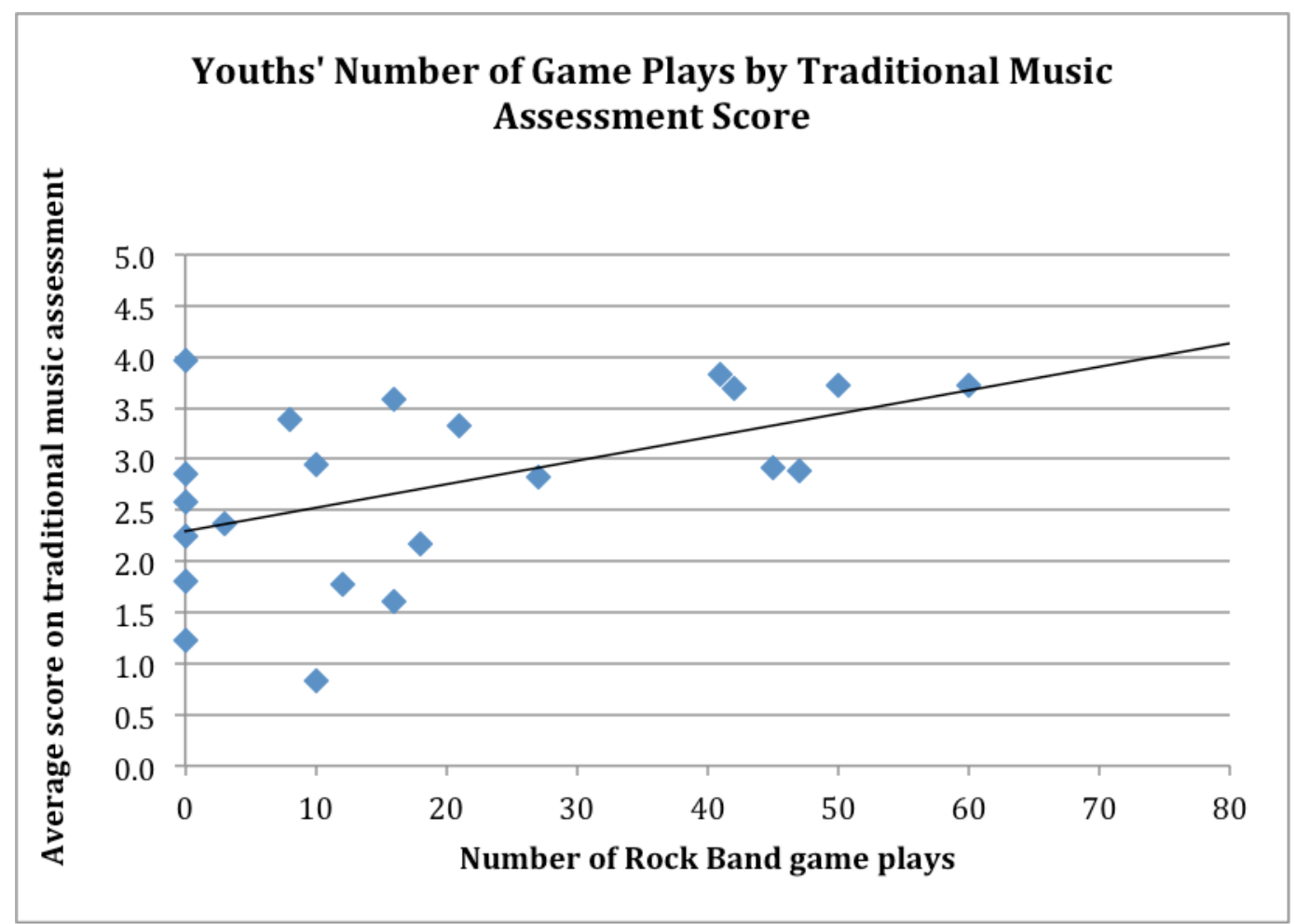

Figure 7. Scatterplot of the number of Rock Band sessions by youth's score on the traditional music assessment.

\section{DISCUSSION \& CONCLUSION}

Collectively, these results reflect that extended play in Rock Band positively correlates with the assessment results of youths' traditional music abilities, providing evidence that the youth playing rhythmic videogames see a connection between the two representational sign systems. While such correlations are not the same as documenting a causal shift, these findings suggest a couple of interesting interpretations of the data: First, it's possible that extended Rock Band play positively impacted the traditional music competencies of novices. Certainly the data suggests that as one engages in more Rock Band sessions, the scores on traditional music assessments go up. However, more evidence, such as pre-test scores and the addition of a control group, would be needed to confirm this interpretation. These types of data and conditions would be difficult, if not impossible, to get in an informal learning environment like the BGC.

Second, an alternative explanation may be that those youth that already are adept at traditional music are more likely to persist in the Rock Band Club. This interpretation suggests that youth that have more traditional music training succeed in playing Rock Band more than their peers. Given our current data, this is an equally plausible possibility. However, even this interpretation suggests that 
youth are making connections from one internalized sign system (in this case, traditional notation) to another (i.e., Rock Band musical notation).

Both interpretations of the data are interesting for our purposes and are novel contributions to the literature. They both suggest that youth are making connections between the two different representational systems of music and that youth that have internalized one system are at an advantage when presented with a new notational system. Our qualitative observations of increased enrollment in private music lessons at the BGC in the wake of the Rock Band Club further support the notion that youth are making connections between their virtual ingame experiences of music performance and more highly-esteemed traditional music education practices (like playing violin, practicing Bach, and reading standard notation), changing perhaps both the identity of the participants as well as their perception of classical music. Perhaps this is because Rock Band differs from most games in that it doesn't simulate as much as it represents actual experience, with a great deal of fidelity to the rhythmic aspects, especially, of music making. As such, the rhythmic concepts embodied in many rhythmic games are one and the same with those central to the core K-12 standards in music education, including the learning of hierarchical structures, levels of subdivision, units of measurement, and pattern identification (as already outlined in this paper). To our knowledge, this is one of the first studies to demonstrate such a relationship between in-game and out-of-game experiences.

A significant reason why rhythmic videogames provide an advantageous introduction to music learning concerns the culture of videogaming and its relationship to the performative aspects of being a musician. For example, youth were not sent into practice rooms to learn music fundamentals; their learning experiences were wrapped within the guise of gameplay and group activity. This proved important not only for youths' sustained engagement, but potentially for the learning, itself. As Green observes, young musicians only interact effectively with music to the extent that they are enjoying themselves. In her observations, as well as our field note excerpts included above, "cooperation, sensitivity to others, commitment and responsibility are explicitly highly valued by the young musicians" (2008, p. 8) and were defining characteristics of participation in Rock Band Club. Comparing the Rock Band Club to the private instrumental lessons at the $\mathrm{BGC}$, the contexts for performance were quite different; the violin and recorder students never gave recitals or official performances for their BGC peers, whereas the Rock Band Club youth treated each session as a performance, with nearby members clapping and dancing to the music blasting from the television. With performance being one of the most rewarding aspects of being a musician, the Rock Band youth (through their displays for the audience and wide grins when their "band" played well together) appeared to get a sense of what that aspect of being a performer was all about much sooner than their private-lesson peers (who would also have to practice much longer on their instruments before having a piece "performance ready"). Without the opportunities for performance, the students in private lessons were engaged in an activity that seemed, at least to 
youth on the outside, to lack in context or function. And, yet, the members of Rock Band Club eventually overcame their earlier apathy toward the idea of taking private lessons, potentially because Rock Band provided them with a venue to forge their identities as musicians. Several field notes highlight how youth entered the Rock Band Club, grabbed the controller (i.e., their instrument), and began mimicking the actions of a rock star (e.g., the guitar over the head and the emphatic arm gestures of professional rock and roll musicians). Though the vast majority of youth in our observations approached their first experience in Rock Band with apprehension, the ability to fast-forward to the rewards of musicianship (even if only communally imagined) appeared to provide them with the context for what making music "the real way" would look like if done successfully. The fact that several of the youth who signed up for private lessons after participating in the Rock Band Club verbally acknowledged that they had been sitting on latent desires to learn an instrument for some time further points to the connections that youth were forging between Rock Band Club and their musical selves.

As some critics are quick to assert "learning to play guitar in Rock Band has nothing to do with playing a guitar in real life," let us first clarify the distinction between the development of instrumental facility and the development of musical understanding and representation. Indeed, in the former case, simplified controllers can't capture the nuance, technical challenges and creative freedom of playing a traditional instrument. In that regard, we would see it as a detriment to youths' musical learning (and to the world at large) if rhythmic games were to replace future musicians' proficiency on live instruments. However, we argue that it's the games notational system (as well as the ways in which the peripherals supporting easy entry for the novice) and the emphasis on the "nuts and bolts" of music that rhythmic games provide their greatest service. By providing somewhat of a "training wheels" version of traditional notation, the game provides broader access to fundamental music concepts such as meter, rhythm, pitch, texture and, perhaps above all else, the relationship between notated and aural representations of music - all of which are directly applicable to performance study on a live instrument. Although we have chosen to focus on rhythm here, it is quite possible that players are learning about other aspects of music such as pitch and ensemble work, which is subject to further study.

While video games have garnered significant attention with regards to learning (c.f., Gee 2007), little attention has been paid to the role rhythmic games could play in after-school learning communities, as well as music learning, in general. We have shown through analyzing learning using a sociocultural framework, that it's possible that Rock Band, and games like it, are fruitful environments for game players to fully immerse themselves in an environment to support musical performance. The representations of music presented in and by Rock Band allows players to engage more deeply with the game content, allowing players to internalize the game's representation in ways that allow players to see commonalities among traditional and non-traditional representations of music. 
This meditational process also provides novice learners with a 'way in' (Wiggins 2009) that moves them from less to more formal practices in more engaging ways.

By extension, this work holds some lessons for how informal and formal learning environments may complement one another more fully. Oftentimes, informal learning environments are conceived of as "free play" or, at the other extreme, as replicas of the formal learning experiences (i.e., longer school days, more direct instruction, etc.). Rock Band provides an interesting alternative. Despite bearing little resemblance to the traditional music education curriculum, Rock Band seems to build a successful and alternative bridge for youth to see and capitalize on the connections to the traditional music community. Cases like those depicted above provide evidence that youth who at one time had little interest in free music lessons, take up these opportunities once they seem relevant and connected to their interests. These examples beg the question, would video games in other areas of the visual and performing arts, or even in other disciplines, support similar types of connections?

\section{REFERENCES}

Abril, Carlos. 2008. Culturally Responsive Teaching in Secondary Instrumental Music: Mariachi as a Case in Point. Unpublished paper presented at the Cultural Diversity in Music Education Nine Symposia 2008, Seattle, Washington, March 2008.

Bamberger, Jeanne, \& diSessa, Andrea. 2003. Music as Embodied Mathematics: A study of a mutually informing affinity. International Journal of Computers for Mathematical Learning 8, 123-160.

Campbell, Don. 1997. The Mozart Effect: Tapping the Power of Music to Heal the Body, Strengthen the Mind, and Unlock the Creative Spirit. New York: William Morrow \& Company.

Cazden, Courtney. 1981. Performance before competence: Assistance to child discourse in the zone of proximal development. Quarterly Newsletter of the Laboratory of Comparative Human Cognition, 3(1), 5-8.

Clements, Ann. 2008. From the Inside Out: The Case Study of a Community Rock Musician. Unpublished paper and poster presented at the Music Educations National Conference Bi-annual Meeting: Milwaukee, Wisconsin, April 2008.

Cole, Michael, \& Engeström, Yrjö. 1993. A cultural-historical approach to distributed cognition. In G. Salomon (Ed.), Distributed cognitions: psychological and educational considerations (pp. 47 87). New York: Cambridge University Press.

Colwell, Richard \& Richardson, Carol. 2002. The new handbook of research on music teaching and learning: A project of the Music Educators National Conference. New York: Oxford University Press. 
Education World. 2008. National Standards Fine Arts: Music. http://www.educationworld.com/standards/national/arts/index.shtml (accessed November 2, 2009).

Fletcher, JC. 2009. "Jack White: learning about music through Guitar Hero is 'depressing'" Joystiq http://www.joystiq.com/2009/06/23/jack-whitelearning-about-music-through-guitar-hero-is-depress/ (accessed September 17, 2009).

Gee, James. 2007. What video games have to teach us about learning and literacy. Second Edition: Revised and updated edition. New York: Palgrave Macmillan.

Green, Lucy. 2002. How popular musicians learn: A way ahead for music education. Burlington: Ashgate.

Green, L. 2005. The Music Curriculum as Lived Experience: Children's "Natural" Music-Learning Processes, Music Educators Journal, 91(4).

Green, Lucy. 2008. Music, Informal Learning and the School: A New Classroom Pedagogy. Hampshire, England, UK: Ashgate Publishing.

Hirsch, Barton. 2005. A Place to Call Home: After-School Programs for Urban Youth. American Psychological Association. Washington DC.

Keene, James. (1982). A history of music education in the United States. Trustees Dartmouth College.

Latour, Bruno. 1988. "Drawing things together". In Representation in Scientific Practice edited by Michael Lynch \& Steve Woolgar 19-68. Cambridge: MIT Press.

Lum, Chee-Hoo. 2009. Musical behaviours of primary school children in Singapore. British Journal of Music Education, 26: 27-42

Masters, Tim. 2009. "Rock stars cool over video games" BBC News http://news.bbc.co.uk/2/hi/entertainment/8242749.stm (accessed September 17th, 2009)

McMillan/McGraw Hill (2005). Spotlight on Music. New York, New York.

Miller, Kiri. 2009. Schizophrenic performance: Guitar Hero, Rock Band, and virtual virtuosity. Journal of the Society for American Music, 4, 395-429.

Missingham, A. 2007. Why console-games are bigger than rock ' $n$ ' roll: What the music sector needs to know and how it can get a piece of the action. http://www.youthmusic.org.uk/assets/files/Console\%20games\%20and\%20 music_1207.pdf (accessed May 22, 2011).

North, Adrian \& Hargreaves, Daniel. 2008. The social and applied psychology of music. New York: Oxford University Press.

PEW Internet and American Life Project. 2008. Teens, video games, and civics. http://www.pewinternet.org (accessed May 1, 2009).

Quillen, David. 2008. Rock Band and Guitar Hero turning gamers into musicians says Guitar Center survey. 1up News. http://www.1 up.com/do/newsStory?cId=3171507 (accessed March 19, 2009).

Rausher, Francis, Shaw, Gordon and Ky, Katherine. 1993. Nature, 365. 611. 
Steinkuehler, Constance. A. 2006. Massively multiplayer online videogaming as participation in a Discourse. Mind, Culture, \& Activity, 13(1), 38-52.

Squire, Kurt. \& Barab, Sasha. 2004. Replaying history: engaging urban underserved students in learning world history through computer simulation games. Published in the proceedings of the 6th International Conference on the Learning Sciences.

Thompson, William Forde, Schellenberg, E. Glenn and Husain, Gabriela. 2001. Arousal, Mood and the Mozart Effect. Psychological Science, 12 (3), 248251.

Väkevä, Lauri. 2010. Garage band or GarageBand®? Remixing musical futures. British Journal of Education, 27, 59-70.

Vygotsky, Lev. 1978. Mind in society: The development of higher mental processes. Cambridge: Harvard University Press.

Wertsch, James, V. 1985. The social formation of the mind. Cambridge, MA: Harvard University Press.

Wiggins, Jackie. 2009. Teaching for Musical Understanding. $2^{\text {nd }}$ Ed. Rochester, MI: Center for Applied Research in Musical Understanding. 